\title{
Experimental validation of an integrated optimization design of a radial turbine for micro gas turbines"
}

\author{
Lei FU ${ }^{\dagger 1}$, Zhen-ping FENG ${ }^{2}$, Guo-jun $\mathrm{LI}^{1}$, Qing-hua $\mathrm{DENG}^{2}$, Yan $\mathrm{SHI}^{2}$, Tie-yu GAO ${ }^{\dagger 2}$ \\ ( ${ }^{1}$ Key Laboratory of Thermo-fluid Science and Engineering of MOE, School of Energy \& Power Engineering, \\ $X i$ 'an Jiaotong University, Xi'an 710049, China) \\ $\left({ }^{2}\right.$ Institute of Turbomachinery, School of Energy \& Power Engineering, Xi'an Jiaotong University, Xi'an 710049, China) \\ †E-mail: leifu@mail.xjtu.edu.cn; sunmoon@mail.xjtu.edu.cn \\ Received Mar. 4, 2014; Revision accepted Oct. 29, 2014; Crosschecked Feb. 10, 2015
}

\begin{abstract}
The aerodynamic performance, structural strength, and wheel weight are three important factors in the design process of the radial turbine for micro gas turbines. This study presents the experimental validation process of this integrated optimization design method by using the similarity theory. Cold modeling tests and investigations into the aerodynamic characteristics were performed. Experimental results showed that the aerodynamic efficiency of the micro radial turbine is $84.3 \%$ at the design point while also satisfying the aerodynamic and strength requirements. Meanwhile, the total weight of the turbine wheel is $3.8 \mathrm{~kg}$ which has only a $52.8 \%$ mass of the original design. This indicates that the radial turbine designed through this technique has a high aerodynamic performance, and thus can be applied to micro gas turbines. The results validated that this integrated optimization design method is reliable.
\end{abstract}

Key words: Micro radial turbine, Integrated optimization design, Bearing and shafting, Performance test doi: 10.1631 jzus.A1400073

Document code: A

CLC number: TK14

\section{Introduction}

Micro radial turbines have aroused much attention from researchers and designers during the past decades, owing to their essential role as a key power unit for distributed generation or distributed energy resources such as micro gas turbines. Some previous studies reported experiments focusing on aerodynamic design and strength optimization of radial turbine wheels.

In the field of aerodynamic designing of micro radial turbines, various aspects have been conducted.

\footnotetext{
${ }^{\ddagger}$ Corresponding author

* Project supported by the National Natural Science Foundation of China (No. 51206126), and the China Postdoctoral Science Foundation (No. 2012M521769)

(iD) ORCID: Lei FU, http://orcid.org/0000-0003-3446-3700; Tie-yu GAO, http://orcid.org/0000-0002-3588-8180

(C) Zhejiang University and Springer-Verlag Berlin Heidelberg 2015
}

Tan et al. (1984) proposed a theory of a large deflection blade design method. Zangeneh-Kazemi (1988) applied Tan et al. (1984)'s method to their 3D flow designing of radial turbines. Yang et al. (1993) and Tjokroaminata et al. (1996) developed this method further and designed radial turbines with splitter blades. Whitfield (1990) developed a unified dimensionless designing method to rationally assess thermodynamic parameters and geometric parameters of micro radial turbines. Ebaid et al. (2002) proposed a uniform designing method of a single-stage radial turbine to optimize the sizes and blade numbers of radial turbines. Huang (1981) studied a turbine blade designing method using a cylindrical parabolic. Feng (1991) investigated the aerodynamic design and analyzed radial turbines focusing on their applications in chemical processes and gas turbines. Deng (2008) discussed the mechanisms of clearance leakage and 
its suppression and performances of micro radial turbines.

Various studies have conducted strength design and optimization of micro radial turbines. Watanabe et al. (2004) experimented on aerodynamic design of radial turbines by using computational fluid dynamics (CFD) and made a finite element analysis and optimization of radial turbines using an inverse design method. Guo (2004) studied blade vibrations of radial turbine whereas Xie et al. (2005) accomplished a strength optimization of radial turbines by changing four of its parameters: inlet and outlet flow angles at blade span, thickness in the middle of the blade tip, and the blade root in the precondition of satisfying its aerodynamic performance requirements. However, few of the studies mentioned above have had a comprehensive and integrated probe into the aerodynamic, strength and weight reduction of micro radial turbines. In view of this, it is necessary to comprehensively design the micro radial turbines and reasonably match the parameters for all the theoretical studies and engineering applications.

Based on the successful design (Feng et al., 2005; Deng et al., 2007a; 2007b) of radial turbines in $100 \mathrm{~kW}$ gas turbines by the TurboAreo Dynamic Research Group in Xi'an Jiaotong University, China, an integrated optimization design of micro radial turbines is developed. In addition, the aerodynamic performance of the micro radial turbine is tested and validated.

\section{Integrated design theory of micro radial turbine}

It is necessary to briefly review the integrated optimization design of micro radial turbines at first. Table 1 shows the design parameters of a radial turbine which is applied for a $100 \mathrm{~kW}$ micro gas turbine. In the process of designing, the wheel was modeled by using a cylinder-parabolic modeling method. Despite the fact that the wheel was cast integratedly and precisely, the radial straight blade on the working wheel and the blade on the inducer wheel can be clearly recognized and identified. As the parabolic modeling method was used, the curvature radius of the blade shape changed from the outer wall to the inner wall, and the flow velocity changes in the flow passage was also uniform. The turbine will obtain the high efficiency as long as reasonable meridional profiles are given.

The integrated optimization designing method of micro radial turbines proposed by Fu et al. (2012) is not a linear design process. Its advantages and disadvantages were both weighed repeatedly, after each iteration, depending on the stage results and optimization of the wheel. Similar procedures were followed for all the iterations. The iteration design is stopped until the new turbine wheel meets aerodynamic and strength requirements with acceptable weight synchronously.

Table 1 Design parameters of the radial turbine

\begin{tabular}{lc}
\hline \multicolumn{1}{c}{ Design parameter } & Value \\
\hline Turbine inlet temperature, $T(\mathrm{~K})$ & 1173.15 \\
Pressure ratio & 2.96 \\
Rotational speed, $N(\mathrm{r} / \mathrm{min})$ & 45000 \\
Flow rate, $G(\mathrm{~kg} / \mathrm{s})$ & 1.1267 \\
Diameter, $D(\mathrm{~mm})$ & 230 \\
Power, $P(\mathrm{~kW})$ & $>300$ \\
Isentropic efficiency & $>80.5 \%$ \\
\hline
\end{tabular}

The integrated optimization designing process was divided into three steps. In the first step, the meridian molded line of the wheel was optimized and the flange diameter and the hub diameter were diminished. In the second step, the main geometrical control parameters of the blade were adjusted accordingly and optimized at the same time. An enlarged angle between the wheel exducer outer end wall and the radial surface of the wheel is acknowledged to be beneficial to the redistribution of stress on the blade surface, which is necessary to disperse or remove the area of high stress on the blade surface. In the third step, the blade obtained in the second step was partitioned into several sections from the hub to the shroud. In every section, the contour of the pressure surface and the suction surface from the leading edge to the trailing edge was renewed by redistributing the blade thickness in this area. The face-center of each section was stacked up again in the space, where the blade in this part was modeled by the free surface modeling method. Then, the wheel was 3D modeled and 11 modifications and optimizations were made to the wheel, with a comprehensive consideration given 
to its total weight and strength. To sum up, the third step is the most sophisticated one in the integrated optimization design method of micro radial turbines because both the blade and the wheel were comprehensively designed at the same time.

After these three steps of optimization, the aerodynamic performance was computed again to ensure that the aerodynamic performance of the radial turbines meets the design requirements. Meanwhile, the total weight of the turbine wheel is reduced from $7.2 \mathrm{~kg}$ to $3.8 \mathrm{~kg}$ which has a $47.2 \%$ less mass. Fig. 1 shows the final design of the micro radial turbine.

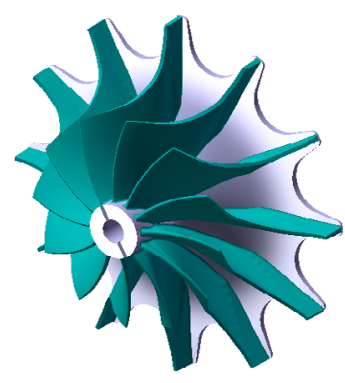

(a)

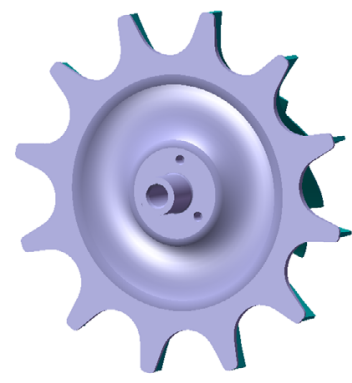

(b)
Fig. 1 3D geometric modeling of the final design wheel (a) Front view; (b) Back view

\section{Experiments on the aerodynamic charac- teristics of the micro radial turbine}

\subsection{Experimental setup}

The final test system for the radial turbines was designed according to the test requirements and the specific circumstances of the labs in the Department of Energy and Power Engineering of Xi'an Jiaotong University (Fig. 2). Fig. 3 illustrates structures of the test platform and its subsystems, which were set up after the completion of the design and location of the experiment system and repeated installing and debugging.

The test platform system is composed of six subsystems, which are: (1) a compressed air supplying subsystem, (2) a bearing lubricating and cooling subsystem, (3) a dynamometer water supplying subsystem, (4) inlet and outlet water valves for dynamometer and controlling subsystems, (5) a turbine performance testing subsystem, and (6) a controlling subsystem for the platform. All the subsystems are to be briefly described and introduced in the next section.

The compressed air supplying subsystem supplies clear and steady compressed air for the test platform. We connected in parallel a two-stage piston

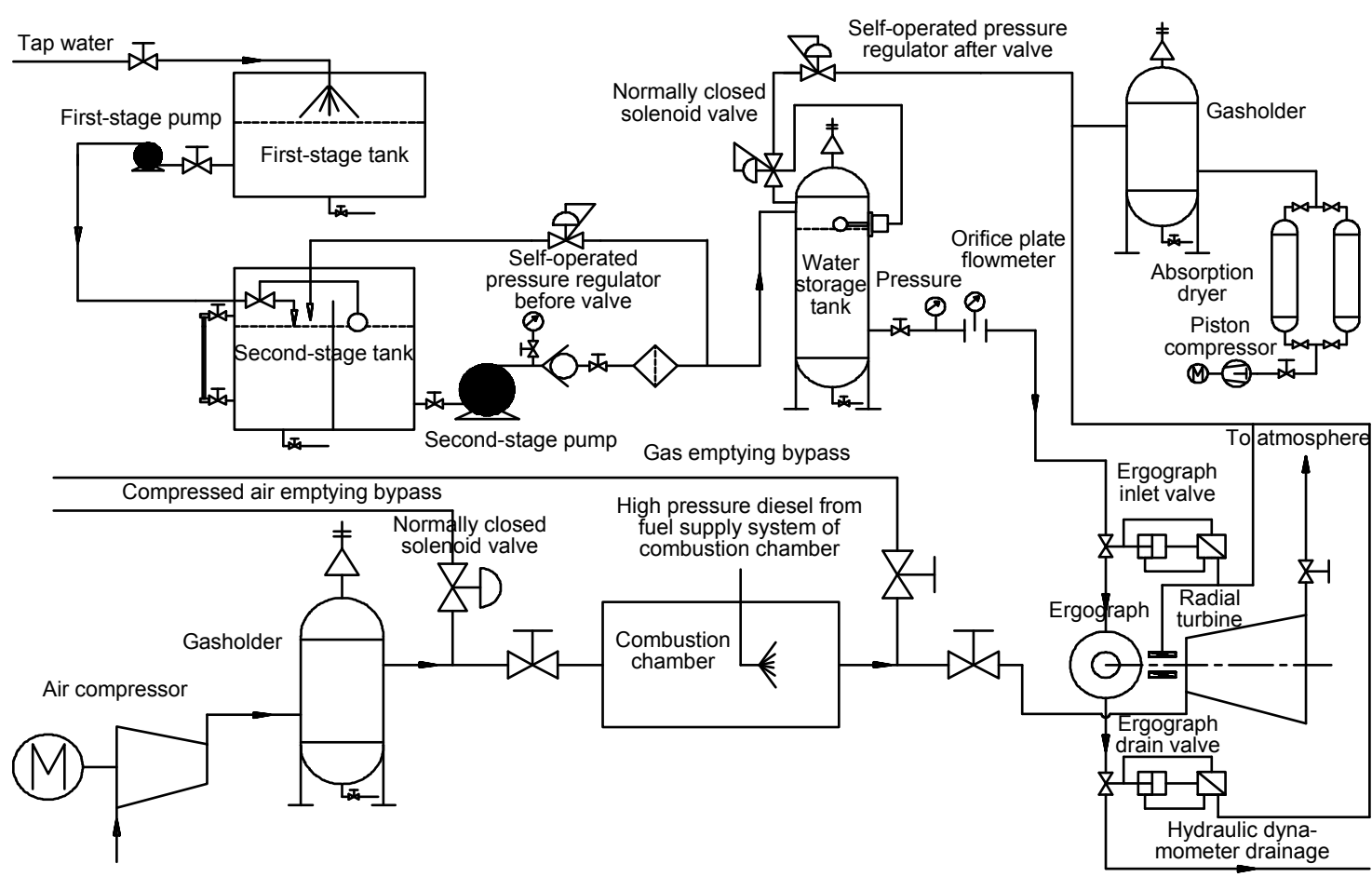

Fig. 2 Schematic design of the final test system of the micro radial turbine 

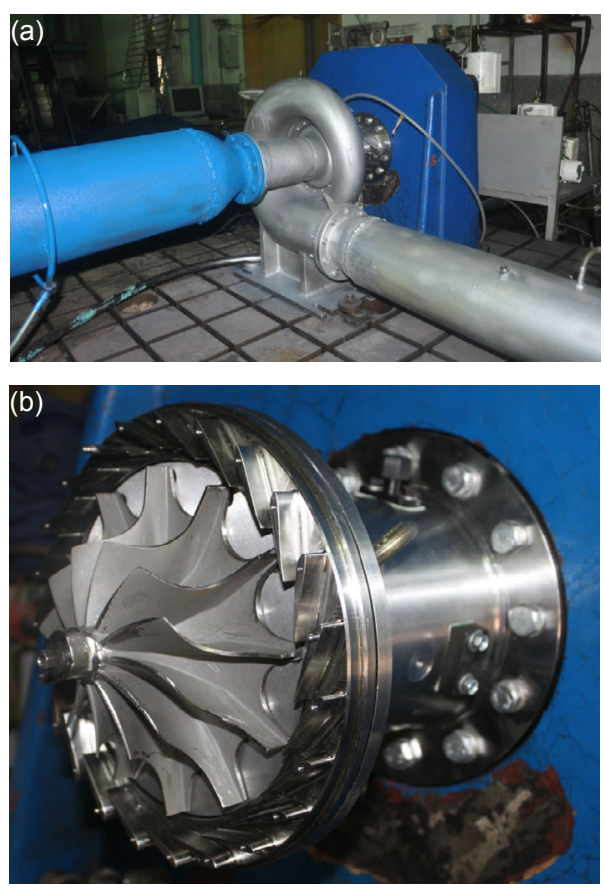

Fig. 3 Constructions of the test platform and its body proper

compressor $\left(700.0 \mathrm{kPa}\right.$ and $\left.10 \mathrm{Nm}^{3} / \mathrm{min}\right)$, two screw compressors $\left(20 \mathrm{Nm}^{3} / \mathrm{min}\right)$, and two new screw compressors $\left(24 \mathrm{Nm}^{3} / \mathrm{min}\right)$.

The bearing lubricating and cooling subsystem lubricates the spherical ball bearing during the test operation at high-speed, and an oil-air lubrication was employed. To accomplish the oil-air lubrication, it is necessary to install special control devices that can continuously adjust oil injection in 10-300 s to circulate normally after injecting oil 90 times in cold start mode or injecting oil 30 times in hot start mode.

The dynamometer water supplying subsystem consists of a two-stage water supply device and a self-made towerless water supply device to ensure a steady and safe operation of the hydraulic dynamometer, with a maximum flow rate of $4.6 \mathrm{t} / \mathrm{h}$ and a water pressure of $0.35 \mathrm{MPa}$. When the towerless water supply device was working, it supplied water to the dynamometer. Meanwhile, the two-stage pump injected water into the water storage tank, and the independently-driven pressure regulating valve on the water pipes adjusted itself to maintain a steady pressure in the tank.

The hydraulic dynamometer in the experiments was used as a consumed power and measured power unit. As the hydraulic dynamometer is a precise measuring instrument, the force transducer used to test the torques was demarcated according to the manual to guarantee the reliability of the testing results. The standard electric signals of the magnetic rotor speed sensor and the tension sensor were transmitted to the controlling platform of the hydraulic dynamometer to obtain the speed and tension of the rotor, which was also imported into the static data acquisition system by the outer terminal to obtain a real-time recording.

Characteristic parameters of the turbine include the inlet total pressure, total temperature, outlet static pressure, flow rate, speed and torque of the turbine. The standard orifice flow meter was used to assess the flow rate. Actually, the first four parameters to be tested were in essence just the pressures and temperatures.

In addition to the above physical quantities assessed to obtain the characteristics of the turbine, some other physical quantities were also assessed to make sure that the test platform operated safely and smoothly. These additional parameters include: bearing temperature of the turbine rotor, bearing temperature of the dynamometer rotor, discharge temperature of the dynamometer, radial vibration displacement of the turbine rotor, and vibration acceleration of the turbine shell. The simulated signals of all the above turbine characteristic parameters and other static physical quantities were transmitted into the IMP static data acquisition board and converted with a conversion card into digital signals to retrieve a real-time recording. Other displacement and acceleration signals were directly transferred into the FOCUS II integrated dynamic signal acquisition and analysis instrument.

\subsection{Design for the bearing and shafting}

The design and adjustment for the bearing and shafting on the test platform included: (1) adding brackets to the volute casing and taking it as a fulcrum to prop up the turbine components; (2) adjusting the three degrees of freedom of the volute casing in height and horizontal directions so as to meet the moderate requirements of the shafting components; (3) shortening the axis of the shafting components and increasing its rigidity; (4) adding a damper system to the supporting structure of the shafting system and improving its rotor dynamic characteristics to ensure 
the steady operation of the rotor on a large scale; (5) designing and adding monitoring components to the shafting system to test the vibration and to prevent the rotor from running away; and (6) designing and configuring the oil-circuit, air-circuit, and water-circuit for the shafting system.

The design and research of the technical criteria of shafting in the present study included: (1) the maximum rotation speed of the shafting system being set at $50000 \mathrm{r} / \mathrm{min}$ and the rotation speed ranging from $10000 \mathrm{r} / \mathrm{min}$ to $50000 \mathrm{r} / \mathrm{min}$ to ensure a steady operation; (2) unless the shafting goes beyond the critical rotation speed, it is necessary to limit the vibration of the shaft end connected with the hydraulic dynamometer below $6.4 \mu \mathrm{m}$ in the radial and axis directions; (3) the processed shafting system has to combine with the radial turbine to conduct the dynamic balance test, whose grade has to be G1.0; (4) under the designed operation condition, an axial stress of $1500 \mathrm{~N}$ in magnitude will generate towards the outlet side of the turbine. According to the engineering experience and relative technical requirements, this radial stress should be amplified and balanced to guarantee a safe operation of the shaft line system; and (5) the opposite moderateness between the shafting system and the main support on the test platform is limited to $0.002 \mathrm{~mm}$ or lower.

\subsection{Locations of the measuring points and pro- cedure of the test}

A high precision Verabar flow meter was located on the straight pipe between the main air valve of the radial turbine and the volute casing inlet. Next to it were placed the thermal resistance and static pressure test holes to assess the density of the airflow. A general pressure probe and a thermal resistance probe were located at the volute casing inlet to record conditions of the inlet air. A static pressure test hole was located at the volute casing outlet to record the circular average static pressure of the exhaust air.

In the present study, the similarity theory was applied to the experiments. For the radial turbine in this study, the wheel, the guide vane, and the volume casing were all manufactured by scaling down to 0.75 times of the original size to secure a sufficiently similar geometry. By using the same pressure ratios, we are able to make sure that the Mach numbers are the same before and after the simulation. And if $n D / \sqrt{R T_{0}}$ are the same before and after the simulation, the Strouhal number is the same.

In equations of this paper, $n$ is the wheel rotational speed, $D$ is the diameter of turbine wheel, $R$ is the gas constant, $T$ is the temperature, $G$ is the mass flow that is flowing through the radial turbine, $P$ is the pressure, $k$ is the adiabatic index of the working substance, $M$ is the torque measured by the hydraulic dynamometer, and $C_{\mathrm{p}}$ is the specific heat capacity under the constant pressure of the working substance. The superscript * means total, the subscripts 0 and 2 mean the inlet and outlet of radial turbine, respectively, and the subscripts $\mathrm{m}$ and $\mathrm{d}$ mean the prototype parameter and corrected parameter, respectively.

The experiment was performed as described and presented as follows: (1) increased the load of the radial turbine by increasing the inflow of the hydraulic dynamometer at an experimental rotation speed until the absorbing power of the dynamometer reached its maximum at this speed; (2) repeated the first step at a higher experimental rotation speed; and (3) increased the experimental rotation speed until the Strouhal number reached or got close to the original turbine value.

Under the condition that the temperature of the inlet pressured air was $308 \mathrm{~K}$, and because the diameter of the experimental wheel was $172.5 \mathrm{~mm}$, the design point rotational speed was about $30000 \mathrm{r} / \mathrm{min}$. With the optimized shafting system, the rotation speed could reach $110 \%$ of the design speed. Namely, the experimental rotation speed can be as fast as $33000 \mathrm{r} / \mathrm{min}$.

\subsection{Data processing}

The parameters of measurements which were employed in experiment are shown in Table 2.

The corrected rotational speed $n_{\text {cor }}$ is considered as a reference variable in the data processing and is represented as

$$
n_{\text {cor }}=\left(D_{\mathrm{m}} n_{\mathrm{m}}\right) / \sqrt{T_{0 \mathrm{~m}}^{*}}
$$

In this experiment, as the corrected rotational speed at the design point $n_{\text {cor-design }}=302.17$, performances of the radial turbine were tested when the relative corrected rotational speed was from $40 \%$ to $110 \%$ of $n_{\text {cor-design. }}$ 
Table 2 Basic parameters of main measurements in experiment

\begin{tabular}{|c|c|c|c|}
\hline No. & Name of instrument & Type and technical index & Measurement precision \\
\hline 1 & $\begin{array}{l}\text { KAHN 401-013 } \\
\text { hydraulic dynamometer }\end{array}$ & Max rotational speed: $50000 \mathrm{r} / \mathrm{min}$ & $\begin{array}{l}\text { Speed: } \pm 0.1 \% \text { full scale; } \\
\text { torque: } \pm 0.1 \% \text { full scale }\end{array}$ \\
\hline 2 & Thermal resistance & I-grade and K-grade $273-353 \mathrm{~K}$ & $\pm 0.5 \mathrm{~K}$ \\
\hline 3 & Flowmeter & Orifice plate and Verabar & $1 \%$ \\
\hline 4 & Rosemount pressure transmitter & $3051 \mathrm{CD}, 3051-\mathrm{CG}$ & $0.075 \%$ full scale \\
\hline 5 & Magnetoelectric speed sensor & NZS & $\pm 0.1 \% \times 50000, \pm 50 \mathrm{r} / \mathrm{min}$ \\
\hline 6 & Eddy current sensor & CWY-DO-810508-02-05-10-02 & Nonlinearity: $0.7 \%$ \\
\hline 7 & PCB acceleration sensor & M356A24 & Frequency deviation: $\pm 1 \%$ \\
\hline 8 & Torque sensor & Hydraulic dynamometer & $\pm 0.03 \mathrm{~N} \cdot \mathrm{m}$ \\
\hline 9 & $\begin{array}{l}\text { Shlumberger static data acquisition } \\
\text { system }\end{array}$ & $\begin{array}{l}\text { IMP static data acquisition board, } \\
\text { 20-channel }\end{array}$ & 10 times $/ \mathrm{s}$ \\
\hline 10 & $\begin{array}{l}\text { High frequency dynamic data } \\
\text { acquisition system }\end{array}$ & $\begin{array}{l}\text { VisionXP 16-channel portable } \\
\text { data recorder }\end{array}$ & $\mathrm{A} / \mathrm{D}$ resolution: 16 bit, $0.05 \%$ \\
\hline
\end{tabular}

The actual mass flow rate of the experiment was to be transmitted to the corrected flow $G_{\mathrm{d}}$ under the original turbine condition as

$$
G_{\mathrm{d}}=\frac{\left[\frac{G \sqrt{T_{0}}}{D_{1}^{2} P_{0}}\right]_{\mathrm{m}}\left[\sqrt{\frac{k}{R}\left(\frac{2}{k+1}\right)^{\frac{k+1}{k-1}}}\right]_{\mathrm{d}} P_{0 \mathrm{~d}} D_{1 \mathrm{~d}}^{2}}{\left[\sqrt{\frac{k}{R}\left(\frac{2}{k+1}\right)^{\frac{k+1}{k-1}}}\right]_{\mathrm{m}} \sqrt{T_{0 \mathrm{~d}}}} .
$$

Finally, the total-static efficiency of the radial turbine $\eta_{\mathrm{t}-\mathrm{s}}$ is calculated by

$$
\eta_{\mathrm{t}-\mathrm{s}}=\frac{1}{9550} \frac{M_{\mathrm{m}} n_{\mathrm{m}}}{G_{\mathrm{m}} C_{\mathrm{p}} T_{0 \mathrm{~m}}^{*}\left(1-\left(\frac{P_{2 \mathrm{~m}}}{P_{0 \mathrm{~m}}^{*}}\right)^{\frac{k-1}{k}}\right)} .
$$

\section{Results and discussion}

The design rotational speed of the micro radial turbine after using the similarity theory was $30000 \mathrm{r} / \mathrm{min}$. With different expansion ratios, the overall performance parameters of the radial turbine were measured when the rotation speed ranged from 0.4 times to 1.1 times of the design rotational speed. Fig. 4 illustrates curves of relations between the corrected parameters and the pressure ratio of the micro radial turbine achieved in the cold modeling test, including the flow passage characteristics and the efficiency characteristics. Because of the greater stability in the higher rotational speed which also close to the design point rotational speed, more data points were captured in the experiments.

Fig. 4a shows that the corrected flow curves of the micro radial turbine had the complete and reasonable changes due to the radial turbine aerodynamic performance. As the same expansion ratio condition, the stage degree of reaction of the turbine increased as the wheel rotational speed increased due to the impact of the centrifugal force. This change caused a decrease of the enthalpy drop in the nozzle guide vane and slowed down the outlet flow velocity, which also resulted in the weakness of the flow passage capacity. Compared to the lower rotational speed, the weakness of the flow passage increased in the higher rotational speed, but the increasing value was also uniform in the higher rotational speed.

In addition, at the same speed, the stage flow passage capacity increases along with the increase of the stage expansion ratios. If the rotational speed is high, the Mach number at the outlet of the nozzle guide vane will accordingly increase owing to the considerably larger stage expansion, which may lead to a choke condition and slow down the increase in the flow passage capacity. At the 0.5 times rotational speed, the maximum experiment data of the mass flow cannot be captured at this moment because of the lower operation stability, but the curve trend is reasonable and regular on an overall basis.

Fig. $4 \mathrm{~b}$ shows the overall performance of the micro radial turbine via the expansion ratio. In Fig. $4 \mathrm{~b}$ 

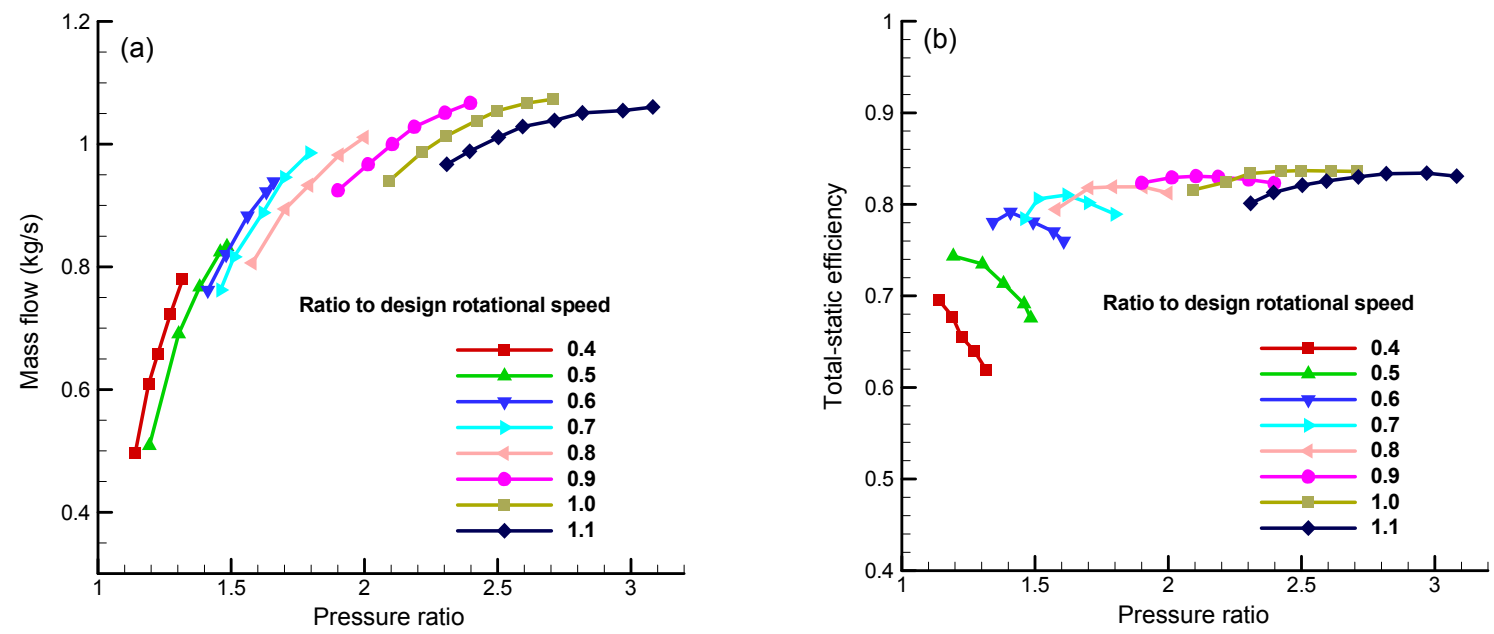

Fig. 4 Overall performance of radial turbine vs. the pressure ratio: (a) corrected flow; (b) total-static efficiency

we can see that at $30000 \mathrm{r} / \mathrm{min}$, the total-static efficiency of this micro radial turbine reaches up to $84.3 \%$. The hydraulic dynamometer operates steadily in the experiment, with all the efficiency curves being basically completely parabolic except when the speed is 0.4 or 0.5 times the design rotational speed. In the case of the latter, the efficiency curves are a right-half parabolic.

If the flow passage capacity is higher than the design point, the stage degree of the reaction of the radial turbine will decrease. With the expansion ratio and rotational speed in the design point condition, the flow may expand excessively in the nozzle guide vane, which leads to the deflection of the velocity triangle from the design point. So the maximum efficiency should appear a bit lower than the design point expansion ratio. In other words, the experiments in this study can avoid this condition throughout the process and when the maximum efficiency point has been taken at the 1.0 times rotational speed exactly with the design point expansion ratio, which also illustrates that the experiments were successful and the data have high reliability.

The experimental results show that the flow passage capacity and the total-static efficiency of the micro radial turbine met all the technical requirements and specifications defined within the engineering requirements. That means the reliability of the integrated optimization design method, which was researched and developed in our precious study (Fu et al., 2012), has been validated.
Due to the aerodynamic and modeling features of the radial turbine, there are some rigorous constraints on the wheel weight-reduction. Usually, the wheel has to maintain a remarkably high aerodynamic level and a satisfactory stress distribution even after the weight-reduction. This has set a more demanding standard for the optimization of the wheel aerodynamics and strength, and thus might be a significant progress for the comprehensive optimization of aerodynamic, strength, and wheel weight for the micro radial turbine. If this problem is solved, it can not only provide a solid foundation for the manufacturing of bearings and turbine aerodynamic characteristic experiments, but also bring about a design margin and reduced design difficulty for bearing design of principle micro gas turbines.

\section{Conclusions}

The experimental validation process of the integrated optimization design method, the cold modeling tests, the investigations into the aerodynamic characteristics, and the experiment analysis results of a turbine wheel for a $100 \mathrm{~kW}$ micro gas turbine, are conducted and presented in this paper.

1. The micro radial turbine and its other experimental parts were developed and processed, and a high-speed and high-precision platform was established and optimized to test the aerodynamic characteristics of radial turbines. The experiments 
successfully solved some critical problems with the test platform, such as the support for rotors and bearings, and some feasible and reliable renovations and solutions have been proposed. The results of the present investigation indicate that the test platform and its subsystems are rationally designed, operated smoothly and its speed rose steadily up to $33000 \mathrm{r} / \mathrm{min}$ in the experiments.

2. Technical improvements have been made in the cantilevered high-speed small shafting with a rotational speed of $50000 \mathrm{r} / \mathrm{min}$-class, an axial stress of $1500 \mathrm{~N}$-class and an inlet temperature of $500 \mathrm{~K}$ class. The dynamic theory of flexible rotor with elastic support has been applied to the design of the matching design between the shafting system and micro radial turbine wheel. This technical modification of the micro radial turbine can meet the operation requirements, prolong its service life, improve its testing efficiency, shorten its test duration, and reduce its testing cost and repair rate.

3. The overall performance parameters of the micro radial turbine were obtained at a speed of 0.4-1.1 times the design rotational speed including the flow passage capacity and efficiency characteristics. At the design speed, the total-static efficiency of the radial turbine reaches up to $84.3 \%$. The experimental results show that under the premise of material strength and weight reduction, the aerodynamic performance of the micro radial turbine is good enough to meet the requirements for engineering applications and can be applied to the $100 \mathrm{~kW}$ micro gas turbines. What is more, the experiment has validated the reliability of the integrated optimization design method of radial turbines, which is to some extent a significant progress in the aerodynamic design and comprehensive design of micro radial turbines.

\section{References}

Deng, Q.H., 2008. Design and Development, Aerodynamic Performance Test, and Tip Clearance Flow Characteristics of a Radial Inflow Turbine for $100 \mathrm{~kW}$ Microturbines. PhD Thesis, Xi'an Jiaotong University, Xi'an, China (in Chinese).

Deng, Q.H., Niu, J.F., Mao, J.R., et al., 2007a. Experimental and numerical investigation on overall performance of a radial inflow turbine for $100 \mathrm{~kW}$ microturbine. Turbo Expo 2007: Power for Land, Sea, and Air, Vol. 3, Montreal, Canada. ASME, USA, p.919-926. [doi:10.1115/ GT2007-27707]

Deng, Q.H., Niu, J.F., Feng, Z.P., 2007b. Tip leakage flow in radial inflow rotor of a microturbine with varying blade-shroud clearance. Turbo Expo 2007: Power for Land, Sea, and Air, Vol. 6, Montreal, Canada. ASME, USA, p.1081-1088. [doi:10.1115/GT2007-27722]

Ebaid, Y., Bhinder, M.S., Khdairi, F.S., et al., 2002. A unified approach for designing a radial flow gas turbine. Turbo Expo 2002: Power for Land, Sea, and Air, Vol. 1, Amsterdam, The Netherlands. ASME, USA, p.1105-1117. [doi:10.1115/GT2002-30578]

Feng, Z.P., 1991. Study of the Internal Flow and Separation Characteristics of Radial Inflow Turbine Impellers. PhD Thesis, Xi' an Jiaotong University, Xi'an, China (in Chinese)

Feng, Z.P., Deng, Q.H., Li, J., 2005. Aerothermodynamic design and numerical simulation of radial inflow turbine impeller for a $100 \mathrm{~kW}$ microturbine. Turbo Expo 2005: Power for Land, Sea, and Air, Reno, Vol. 1, Nevada, USA ASME, USA, p.873-880. [doi:10.1115/GT2005-68276]

Fu, L., Shi, Y., Deng, Q.H., et al., 2012. Integrated optimization design for a radial turbine wheel of a $100 \mathrm{~kW}$-class microturbine. Journal of Engineering for Gas Turbines and Power, 134(1):012301-1/8. [doi:10.1115/1.4004162]

Guo, S., 2004. Blade vibration of radial micro gas turbines. The 10th International Symposium on Transport Phenomena and Dynamics of Rotating Machinery, Honolulu, Hawaii, Paper No. 097.

Huang, X.C., 1981. Cylindrical Parabola Curve Blade Shaping Calculate of Radial Impeller and Mathematics Equation. National Defense Industry Publisher, Beijing, China (in Chinese).

Tan, C.S., Hawthorne, W.R., McCune, J.E., et al., 1984. Theory of blade design for large deflections: part II-annular cascades. Journal of Engineering for Gas Turbines and Power, 106(2):354-365. [doi:10.1115/1.3239572]

Tjokroaminata, W.D., Tan, C.S., Hawthorne, W.R., 1996. A design study of radial inflow turbines with splitter blades in three-dimensional flow. Journal of Turbomachinery, 118(2):353-361. [doi:10.1115/1.2836650]

Watanabe, H., Okamoto, H., Guo, S., et al., 2004. Optimization of microturbine aerodynamics using CFD, inverse design and FEM structural analysis (2nd Report, Turbine Design). Turbo Expo 2004: Power for Land, Sea, and Air, Vol. 5, Vienna, Austria. ASME, USA, p.1545-1552. [doi:10.1115/GT2004-53583]

Whitfield, A., 1990. The preliminary design of radial inflow turbines. Journal of Turbomachinery, 112(1):50-57. [doi:10.1115/1.2927420]

Xie, Y.H., Deng, Q.H., Feng, Z.P., et al., 2005. Strength design and numerical analysis of radial inflow turbine impeller for a $100 \mathrm{~kW}$ microturbine. Turbo Expo 2005: Power for Land, Sea, and Air, Vol. 1, Reno, Nevada, USA. ASME, USA, p.881-888. [doi:10.1115/GT2005-68302]

Yang, Y.L., Tan, C.S., Hawthorne, W.R., 1993. Aerodynamic design of turbomachinery blading in three-dimensional flow: an application to radial inflow turbines. Journal of Turbomachinery, 115(3):602-612. [doi:10.1115/1.2929297]

Zangeneh-Kazemi, M., 1988. Three-dimensional Design of Radial Inflow Turbines. PhD Thesis, University of Cambridge, Cambridge, England. 


\section{中文概要}

\section{题 目: 微型燃气轮机向心浴轮一体化寻优设计方法的试 验验证}

目 的：根据微型燃气轮机的特点及其应用领域, 针对其 核心部件向心浴轮的设计, 提出一体化寻优设计 方法, 并搭建向心浴轮性能试验台进行试验验 证, 以期检验一体化设计方法的可靠性，获得微 型向心浴轮高转速性能试验方法并解决性能试 验中出现的实际问题。

创新点：1. 一体化设计方法是以向心浴轮气动性能、叶轮 材料强度和叶轮整体重量为优化目标的全新寻 优设计方法; 2. 针对悬臂式高速小型轴系解决微 型向心浴轮高速试验轴承轴系设计问题。
方 法: 1. 搭建和完善包含多个子系统的试验台, 并给出 轴承设计的结果; 2. 根据相似理论和微型向心浴 轮一体化寻优设计结果, 对原型进行模化及浴轮 试验件的加工; 3. 开展微型向心浴轮高速性能试 验, 针对向心浴轮的通流特性和效率特性进行试 验数据采集和结果分析, 并评估和验证微型向心 浴轮一体化寻优设计方法的可靠性和应用性。

结 论: 1. 在满足材料强度和整体重量要求的前提下, 叶 轮气动性能仍具有较高的水平, 可应用于 $100 \mathrm{~kW}$ 级微型燃气轮机。2. 试验工作验证了本文提出的 向心浴轮一体化寻优设计方法的可靠性, 发展了 微型向心浴轮的综合设计方法, 以期在工程领域 得到进一步的应用。

关键词: 微型燃气轮机; 向心浴轮; 一体化设计方法; 性 能试验 